\title{
PlatformTutorialSummary
}

\section{How to Get Funding for Instrumentation When Budgets Are Tight}

\author{
Christine A. Brantner, Moderator
}

George Washington University, 800 22nd Street, NW, Suite B2800, Washington, D.C. 20052

chrisbrantner@email.gwu.edu

This is a summary of highlights from presentations given in Tutorial X45 at the Baltimore M\&M meeting August 7, 2018. This session was a two-part tutorial with grantees invited to share their grant writing experiences and representatives from granting agencies invited to share tips on how to successfully secure money for instrumentation. Most of our institutions cannot go out and spend millions of dollars on instrumentation just because we think that we need it. So here are some strategies that might help us to procure funding for instrumentation.

\section{Grantees}

\section{Development of an Acquisition Instrumentation Program}

L. Amelia Dempere, Director, Research Services Centers, Herbert Wertheim College of Engineering, University of Florida

Dr. Dempere first suggested that it is helpful to seek participation on a panel evaluating grant proposals to any of the major funding agencies. This can be done by communicating with the Program Manager of a program in an agency that you are interested in learning more about. Secondly, she advises to propose something unique because it is not sufficiently persuasive to just request the replacement of an old instrument for one newer. A good path is to use a combination of techniques in an instrument that will enable research approaches that the PIs and your institution want to become known for. Be sure to clearly state who will benefit from the new instrument: will it be only internal users and collaborators or will users from other institutions benefit. Third, Dr. Dempere reminds us that having suitable space for the instruments and a strong broader impact plan are important in the proposal. Use your 15 pages wisely by showing strategic figures and visuals that reduce lengthy descriptions and explanations.

\section{Acquisition of a Microscope for In Situ Studies of Hard and Soft Matter}

James M. LeBeau, Associate Director, Analytical Instrumentation Facility, North Carolina State University

Dr. LeBeau started by telling us that we should have a broad range of capabilities that our institution is interested in covering with the instrument we are requesting money for and that we need to be sure to explain each in detail in our proposal. Make a statement about the proposed new capabilities versus the old ones. It is best if you can be unique in your area for capabilities. One secret that he shared is that the instrument that you request does not have to be state-of-the-art, it simply needs to cover your requirements. Dr. LeBeau recommends a primary focus on three to five key ideas with a core group of researchers. Be sure to include the grant numbers that the instrument will impact. Preliminary data is another big item that you want to be sure to add to your proposal where possible. Further suggestions are: plan your submission early so that you can include your researchers and their data; determine if your institution has an internal competition that you must participate in before actual submission to the granting agency; and make a plan to integrate the requested instrument into the Core Facility on your campus.

\section{A New Field Emission Scanning Electron Microscopy Facility with STEM and EDS Capabilities for Interdisciplinary Research and Education at Towson University}

Vonnie D. Shields, Associate Dean and Professor of Biology, Towson University

Dr. Shields spoke to the audience about five interdisciplinary female faculty members from Towson University who were awarded an NSF MRI award. Among her recommendations were: know your institution's classification and its limits for applications so you can choose the NSF Division that best suits the needs of your researchers as well as your institution. It is important to negotiate the cost sharing upfront with your administration so that your proposal meets this requirement. She recommends doing homework on which instrument will best suit your needs by creating a rapport with the vendors, discussing your needs, visiting sites for demonstrations, and sending samples to obtain a data set for your projects to show what is possible if you receive the award. Their proposal discussed the research of each member and included letters of support from other colleges and collaborators to show a broader impact for the instrument. Also discussed were the teaching and outreach activities that would be impacted by the instrument. Be sure to include all the people and groups who will benefit from the instrument.

\section{A Guide to Submitting a Successful NIH S10 Shared Instrumentation Grant Application}

Frank P. Macaluso, Director, Electron Microscopy Analytical Imaging Facility, Albert Einstein College of Medicine

Mr. Macaluso provided listeners with many good tips on writing a successful instrumentation grant, drawing on 
knowledge from several successful awards. Always follow the details and directions for the program that you are applying to. Plan your proposal early so that all of the participants and components are ready to go before the deadline. He recommends that you choose your PIs with purpose; select major users whose grant-funded research can be impacted by the instrument. Demos will help you and your researchers obtain preliminary data to show this impact. The directors from his Core wrote the majority of the proposal with assistance from the PIs who wrote several pages about their research. The directors were sure to include information on the technical expertise of their staff who will enable the best utilization of the instrument. You should state the business model for your Core to help the proposal reviewers understand how the instrument will be used at your institution. All of this is your justification to demonstrate your institution's need for this instrument. Mr. Macaluso suggested that we obtain technical specifications from the vendors of like instruments, compare them, and indicate which would best serve the needs of the institution. Don't forget that a letter of support and approval for your proposal submission from your institution along with a financial commitment are very important.

\section{Granting Agencies}

\section{Opportunities for Instrumentation Funding}

Robert Kokoska, Program Manager for Microbiology, Life Sciences Division, US Army Research Office (https://www.onr.navy. mil/Science-Technology/Directorates/office-research-discoveryinvention/Sponsored-Research/University-Research-Initiatives/ DURIP.aspx)

Dr. Kokoska, from US Army Research Office (ARO), described the Defense University Research Instrumentation Program (DURIP) as a source for instrumentation funding that can provide new capabilities in support of Army-relevant high-risk, high-payoff basic research at universities. There are a number of important elements that go into a successful DURIP proposal. These include a detailed description of the supporting research and how it supports the Army mission; details about the impact that the instrumentation will have on the described research and that of others at the same institution as a shared resource; and the educational opportunities that the instrument will provide. A discussion with the ARO program manager whose program aligns with an investigator's research area of interest is highly recommended to ensure that a proposal is competitive and meets the goals of ARO. This program funded 40-50 proposals in 2017 at an average of $\$ 150,000$. The most up-to-date information on the DURIP program can be found in the Army Research Office Broad Agency Announcement. The DURIP announcements are usually posted every year in the March/April timeframe.

\section{The Major Instrumentation Program at the National Science Foundation}

Guebre X. Tessema, Program Director, Division of Materials Research, National Science Foundation (https://www.nsf.gov/ funding/pgm_summ.jsp?pims_id=6672) NSF18-513

Dr. Tessema spoke to the audience about the NSF Major Instrumentation Program. There are two tracks for different amounts of money: Track 1 for $\$ 100,00-\$ 1,000,000$ and Track 2 for $\$ 1,000,000-\$ 4,000,000$. This competitive program received 850 proposals in 2017 across all fields supported by NSF and funded about 134 (17\%). The proposals are reviewed January to May each year. He describes this program as one designed to support proposals to purchase or develop instruments for broad, interdisciplinary research. You should include a management plan for the instrument, the IT required, the staff, the cost structure, the space for the instrument, the number of expected users, and the plan for instrument access. For $\mathrm{PhD}$ granting institutions, there should be a $30 \%$ cost-sharing in the plan from your institution, using funds from non-federal sources, and you need to show a track record of support by the institution as well as good stewardship of previous MRI awards. For instrument development, your proposal should push the state-of-the-art beyond what is currently commercially available. In describing the intellectual merit (the science) in an NSF supported field, be sure to address the "So What?" factor to explain the impact of the instrument that you would like to acquire, purchase, or develop. The NSF MRI program review criteria include a broader impact component. This includes the broader scientific and technical impact as well as the impact on education and training of a diverse, broad workforce. How will the instrument support or enhance programs for local and regional school-age students and minorities, either existing or to be implemented? This program does not support infrastructure, facility construction, or medical research.

\section{NIH's Shared Instrumentation Program: The More I Know, the Better My Chances} Malgorzata Klosek, Scientific Review Officer, Office of Research Infrastructure Programs, National Institutes of Health Shared Instrumentation Grant Programs: (https://grants.nih.gov/grants/guide/pa-files/PAR-18-600.html) (https://grants.nih.gov/grants/guide/pa-files/par-18-599.html)

Dr. Klosek described for us the NIH S10 Instrumentation grants. This program receives an average of 400 proposals every year with 100 awards given out. The awards range from $\$ 50,000-\$ 2,000,000$ and need to be used for state-of-the-art commercial instrumentation. Supplies and service contracts cannot be purchased as part of the award. At the end of the award period, the instrument needs to be installed and functional. Reviewers rely on input from the study section for funding of these awards. She advises that your proposal should describe how your shared resource is going to impact three $\mathrm{NIH}$-funded investigators and $10-15$ users. Your financial plan does not need to include cost sharing, but instrument users, space, and long-term operational costs should all be described in detail. Program managers like to see these grants given to institutions where the instrument will go into a Core Facility. It is useful to have an advisory committee to oversee use of the instrument.

\section{Additional Information}

Anastas Popratiloff, Director, George Washington University Nanofabrication and Imaging Center

Dr. Popratiloff has been on several study sections for instrumentation grants, and he offers us this advice. You can go to the website for NIH S10 Peer Review Critique Instructions and see how people that review grant proposals are 
instructed to review them. This will give you some insight into what the reviewers are looking for in a grant proposal and what is required for a successful proposal. You should think like a reviewer. Tell your research story in your proposal and then think about what the criticisms could be from reviewers. It is always a good idea to serve as a grant reviewer to obtain the insight into how the program functions. Here are the websites:

https:/grants.nih.gov/grants/peer/critiques/s10.htm

https://grants.nih.gov/grants/peer/guidelines_general/ Review_Criteria_at_a_glance.pdf

https://grants.nih.gov/grants/peer/guidelines_general/ scoring_system_and_procedure.pdf

Christine A. Brantner, Senior Research Scientist, Electron Microscopy, George Washington University Nanofabrication and Imaging Center

I admit that I have never written a grant proposal, but I want to reiterate some of the many important ideas our speakers emphasized. Please note that the above article comes from my notes, and I apologize if I have misrepresented anything that our presenters told us. It is not my intention, simply a lack of memory.

To make your proposal strong, pay attention to all details, and maybe the most important and most mentioned tip from our speakers was to answer the questions before the reviewers can ask them. Be sure to read and understand all of the fine print in the funding announcement. Remember that you can have a conversation with the Program Officer to clarify what you have written. I like the following two ideas if they are possible in the program that you are applying to: add additional years of warranty or service contract and ask for application days so that these training days are there when you need them. You will need a well-thought-out management plan for everything from utility hook-ups to user fees. Make clear which fee is charged to whom and how disputes are settled. Put time into this section. Again, plan ahead, allow time to arrange all of the components of the grant application, and apply early. It is often very helpful to have others critique the proposal, and this is easier when everything is finished well ahead of the deadline to provide time for your readers. ATTENTION TO DETAILS cannot be mentioned enough as it seems that many proposals are not even read by the reviewers because of technicalities or because the directions were not followed.

There also are the following federal agencies offering grant possibilities: Office of Naval Research (ONR), Air Force Office of Scientific Research (AFOSR), US Department of Defense (DOD_grants.gov), and US Department of Energy Office of Science. Further information regarding funding opportunities can be found in a series of Microscopy Today articles, from a similar symposium at the Nashville 2011 M\&M meeting, in the following issues: July 2012, page 54; Sept. 2012, page 60; Nov. 2012, page 54; Mar. 2013, page 52; May 2013, page 40; and July 2013, page 42 .

\section{CAMBRIDGE}

\section{Scanning Electron Microscopy for the Life Sciences}

\section{Heide Schatten}

University of Missouri, Columbia

US\$120.00: Hb: 978-0-521-19599-7: $312 \mathrm{pp}$

Recent developments in scanning electron microscopy (SEM) have resulted in a wealth of new applications for cell and molecular biology, as well as related biological

\section{New to the Advances in Microscopy and Microanalysis book series!}

disciplines. It is now possible to analyze macromolecular complexes within their three-dimensional cellular microenvironment in near native states at high resolution, and to identify specific molecu les and their structural and molecular interactions. New approaches include cryo-SEM applications and environmental SEM (ESEM), staining techniques and processing applications combining embedding and resin-extraction for imaging with high resolution SEM, and advances in immuno-labeling. With chapters written by experts, this guide gives an overview of SEM and sample processing for SEM, and highlights several advances in cell and molecular biology that greatly benefited from using conventional, cryo, immuno, and high-resolution SEM.

\section{About the series}

The Press currently publishes the Microscopy and Microanalysis (MAM) journal in conjunction with the MSA, which reaches 4,000 microscopists and is affiliated with 12 international microscopy societies. The series would be a natural development from this journal, and will take a broad view of the discipline, covering topics from instrumentation to imaging, methodology and analysis across physical science, materials science, biology and medicine. Books commissioned for the series will range from advanced undergraduate textbooks through to research and practitioner oriented monographs for researchers. The series aims to produce a coherent source of material, encouraging the communication and exchange of ideas across these divergent fields, ensuring that the series appeals to a broad community in the physical and life sciences.

\section{Forthcoming titles in this series:}

Microscopic Nanocharacterization of Materials

by Michael Isaacson

Energy Filtered Electron Microscopy and Electron Spectroscopy by Richard Leapman

Dynamic Transmission Electron Microscopy

by Nigel Browning, Thomas LaGrange, Bryan Reed,

Henning Stahlberg, Bradley Siwick 